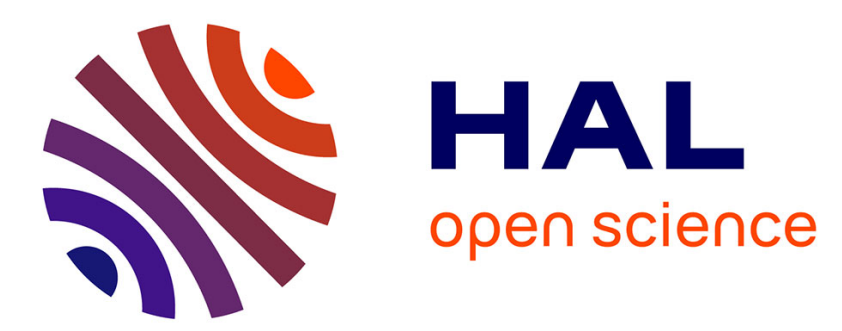

\title{
A SIMPLE TECHNIQUE FOR MEASURING DOPING EFFECTS ON DISLOCATION MOTION IN SILICON
}

\author{
S. Roberts, P. Pirouz, P. Hirsch
}

\section{To cite this version:}

S. Roberts, P. Pirouz, P. Hirsch. A SIMPLE TECHNIQUE FOR MEASURING DOPING EFFECTS ON DISLOCATION MOTION IN SILICON. Journal de Physique Colloques, 1983, 44 (C4), pp.C475-C4-83. 10.1051/jphyscol:1983409 . jpa-00222848

\section{HAL Id: jpa-00222848 https://hal.science/jpa-00222848}

Submitted on 1 Jan 1983

HAL is a multi-disciplinary open access archive for the deposit and dissemination of scientific research documents, whether they are published or not. The documents may come from teaching and research institutions in France or abroad, or from public or private research centers.
L'archive ouverte pluridisciplinaire HAL, est destinée au dépôt et à la diffusion de documents scientifiques de niveau recherche, publiés ou non, émanant des établissements d'enseignement et de recherche français ou étrangers, des laboratoires publics ou privés. 


\author{
S.G. Roberts, P. Pirouz and P.B. Hirsch \\ Department of Metallurgy and Seience of Materials, University of Oxford, \\ Parks Road, Oxford OX1 3PH, U.K.
}

Résumé - Une technique basée sur la microindentation a été développée pour étudier l'influence du dopage sur les mouvements de dislocations dans les semiconducteurs et les isolants. Celle-ci permet l'étude de l'effet du dopage à l'aide d'un équipement simple et de spécimens petits et facilement préparés. Cette technique requiert une indentation à haute température à l'aide d'un testeur de microdureté étalon équiré d'un étage chauffant, suivie d'un recuit contrôlé et d'une attaque acide pour révéler les rosettes de dislocations autour des indentations. La taille de la rosette indique la facilité de mouvement des dislocations dans ce matériau. Un modèle d'interaction de dislocations à l'intérieur du champ de contrainte de l'indentation résiduelle a été développé; ce modèle permet une évaluation de la contrainte critique minimale pour le mouvement des dislocations.

Des résultats préliminaires sur des spécimens de silicium à $400^{\circ} \mathrm{C}$ ont montré que la taille des rosettes était la plus petite pour le silicium intrinsèque, et qu'elle augmentait avec l'augmentation du dopage, les dopants de type ' $n$ ' étant plus efficaces que les dopants de type ' $p$ '. Les valeurs observées pour la "contrainte critique" varient de $\approx 100 \mathrm{MPa}$ (silicium intrinsêque) à $\sim 70 \mathrm{MPa}$ (siliciumfortement dopé de type ' $n$ '). Ces résultats sont bien corrèlés avec ceux d'autres etudes sur les effets du dopage sur la vitesse des dislocations (par exemple : George et Champier, phys. Stat.Sol.53a(1979)529).

Abstract - A microindentation-based technique has been developed to investigate the influence of doping on dislocation motion in semiconductors and insulators. It allows investigation of the doping effect using simple equipment and, small, easily-prepared, specimens. The technique involves high temperature indentation using a standard microhardness tester equipped with a hot-stage, followed by controlled annealing and etching to reveal the dislocation arrays

('rosettes') around indentations. The size of the rosette is indicative of the ease of dislocation motion in the material. A model of dislocation interactions within the residual indentationstress field has been developed; the model allows the evaluation of a critical minimum stress for dislocation motion.

Preliminary results on silicon specimens at $400^{\circ} \mathrm{C}$ have shown that rosette sizes are smallest for intrinsic silicon, and increase with increasing doping, with n-dopants being more effective than p-dopants. Derived values of the 'critical stress' vary from $\approx 100 \mathrm{MPa}$ (intrinsic silicon) to ? $70 \mathrm{MPa}$ (heavily doped n-type silicon). These results correlate well with other workers' results for doping/dislocation velocity effects (e.g. George and Champier, Phys. Stat. Sol. 53a (1979) 529).

Introduction - The mobility of dislocations in semiconductors has been known for some time to be affected by the type and concentration of dopants, i.e. by the position of the Fermi level in the band gap $/ 1 /, / 2 /, / 3 /$. Several models have been proposed for this effect /4/ - /8/ and these have been critically reviewed by Hirsch /9/. This paper reports preliminary results from a study investigating the effects of the doping of semiconductors and insulators on the microhardness-related behaviour of these 
materials. Previous studies of doping effects on dislocation motion required large specimens for mechanical tests or for measurements of dislocation velocity. The method outlined here requires only very small amounts of material. (even $1 \mathrm{~mm}^{2}$ is sufficient for a large number of hardness tests), and the experimental technique is simple.

\section{Experimental Methods}

Materials - The materials used were float-zone silicon, supplied by Wacker Chemitronic TGermany) and Czochralski silicon, supplied by RSRE (Malvern) (courtesy of Dr K.G. Barraclough). Doping levels (both $\mathrm{p}-$ and $\mathrm{n}$-type) range from $10^{12}$ to $2 \times 10^{18}$ atoms $\mathrm{cm}^{-3}$; details of the specimens used are given in table 1 . Specimens were aligned by back-reflection Laue methods and sectioned, using a diamond-impregnated-wire saw, parallel to $\{100\}$. The sections were polished in SiC grit paper and $6 \mu \mathrm{m}$ and $1 \mu \mathrm{m}$ diamond paste to a mirror finish and then polished using recirculating 'Syton' for 3-5 hours to remove any residual surface polishing damage.

Table 1 - Doping Levels in Specimens

$\begin{array}{ccr}\text { Code } & \text { Type } & \text { Doping Level }\left(\mathrm{cm}^{-3}\right) \\ \text { IF } & \mathrm{p}, \mathrm{FZ} & 10^{12} \\ \mathrm{LP} & \mathrm{p}, \mathrm{Cz} & 7 \times 10^{24} \\ \mathrm{LN} & \mathrm{n}, \mathrm{Cz} & 2 \times 10^{25} \\ \mathrm{PC} & \mathrm{p}, \mathrm{Cz} & 2 \times 10^{18} \\ \mathrm{NC} & \mathrm{n}, \mathrm{Cz} & 2 \times 10^{18} \\ \mathrm{NF} & \mathrm{n}, \mathrm{FZ} & 2 \times 10^{18}\end{array}$

Indentation and Etching - Specimens were indented using an 0lympus MHT1 microhardness tester equipped with a hot-stage. The diamond (Vickers profile) was not heated. All results reported here are from specimens indented at a temperature of $400^{\circ} \mathrm{C}$. A $10 a d$ range of $10-200 \mathrm{~g}$ was used, and the indentations were aligned with diagonals parallel to $\{110\}$. Since the diamond could act as a heat sink, all specimens were annealed (in air) for 30 minutes at $400^{\circ} \mathrm{C}$ after indentation. In this way, the rosettes (see below) could form at a well-defined temperature in the residual stress field.

Indentation diagonals were measured using the micrometer eyepiece in the MHT1. Specimens were then etched using the reagent described by Secco d'Aragona /10/ and used by $\mathrm{Hu}$ in his extensive studies of dislocation rosettes in silicon at high temperatures $(\mathrm{e} . \mathrm{g}$. Hu /11/). The etch consists of 1 part of $0.25 \mathrm{M}$ potassium dichromate solution to 4 parts of $40 \% \mathrm{HF}$. Etching was performed at room temperature; times of $10-90 \mathrm{sec}$. were found to produce good rosettes, the $n$-type silicon requiring the longest etching times. The rosette sizes were measured from optical micrographs.

Indentation Rosettes - In hard single crystal materials, under suitable circumstances, dislocations can propagate from the heavily plastically deformed zone close to the indentation into the 'elastic hinterland' and form crystallographically-oriented arrays called rosettes. The original studies of Gilman and Johnston /12/ on rosettes in LiF showed the potential of the technique for studying the relations between microstructure, dislocation motion and macroscopic yield and flow properties. Much work has since been performed on rosette structures in other materials, such as Mgo, $\mathrm{NaCl}$ and $\mathrm{Si}$. The arrangement of the rosette and its component dislocations is highly dependent on the slip systems of the material and the crystallographic alignment of the specimen for indentation. The dislocation configuration forming a rosette on a $\{100\}$ surface of silicon is shown in fig. 1 (after Hu /13/).

Results - The results presented here are from specimens of five different doping levels, and of both Float-Zone (FZ) and Czochralski ( $\mathrm{Cz}$ ) types, as shown in table 1.

Indentation diagonals were measured at room temperature, using the curtain eyepiece in the microhardness tester. For any given load the indentation diagonal, and thus the microhardness, was found to be effectively independent of doping, as shown in table 2 . 


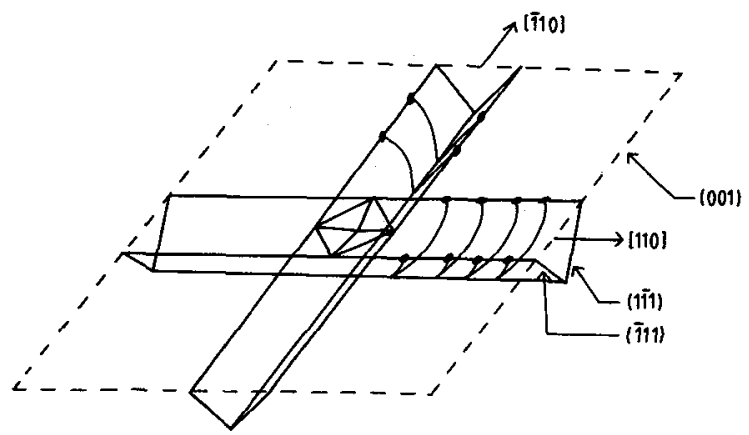

Fig. 1 - Form of indentation rosette on a $\{100\}$ silicon surface (after Hu /13/). The rosette appears as lines of dislocation etch pits on the surface.

Table 2 - Indentation Diagonal Sizes

Specimen

Indentation Diagonal $(\mu \mathrm{m})$ at loads:

$\begin{array}{lccccc} & 10 \mathrm{~g} & 25 \mathrm{~g} & 50 \mathrm{~g} & 100 \mathrm{~g} & 200 \mathrm{~g} \\ \text { IF } & 5.7 & 8.3 & 11.0 & 15.7 & 21.7 \\ \text { LP } & 4.5 & 8.1 & 10.7 & 14.8 & 22.2 \\ \text { LN } & 4.8 & 7.8 & 10.5 & 15.1 & 21.9 \\ \text { PC } & 5.4 & 8.0 & 10.4 & 14.9 & 21.2 \\ \text { NC } & 5.1 & 8.0 & 10.4 & 15.2 & 21.9 \\ \text { NF } & 4.9 & 7.2 & 10.4 & 14.4 & 21.4\end{array}$

Rosette sizes varied in a systematic way between the five specimen types, as shown in figures 2 and 3 . Some typical rosettes are shown in figure 4 . At each load, except at $10 \mathrm{~g}$ where the errors are much larger than the differences between data points, the rosettes are progressively larger in the order (IF, LP, LN), PC, NC, NF (see table 3). This implies that dislocation motion is easiest in float-zone heavily doped n-type silicon and hardest in 'intrinsic' silicon - i.e. where the extrinsic carrier concentration is much lower than the intrinsic carrier concentration $\left(\sim 10^{16} \mathrm{~cm}^{-3}\right.$ at $400^{\circ} \mathrm{C}$ ). At a given doping concentration, dislocation motion seems easier in n-type than in p-type, and in float zone than in Czochralski, silicon. Each point is derived from data from at least 12 indentations (24 indentations at the $50 \mathrm{~g}$ load). The errors in the data points (at loads $>10 \mathrm{~g}$ ) are such that the adjacent points at each load form just distinguishable groups. Measurements from particularly well-formed rosettes always gave values very close to the mean for each group, however, and the linear trends shown in figure 3 indicate that there are consistent and well-characterised differences in the rosette sizes between all the specimen types tested here.

\section{Analysis}

Indentation Stress Fields - The first stage of the analysis carried out was based on evaluating the resolved shear stresses on the dislocations in the rosettes. The method used by $\mathrm{Hu} / 11 /$ could not be used here, as it depends on being able to locate the position of several individual dislocations. At the low temperatures used in these experiments, the rosettes consisted of densely packed dislocations (see figure 4), and individual dislocations cannot be readily identified. However, the 


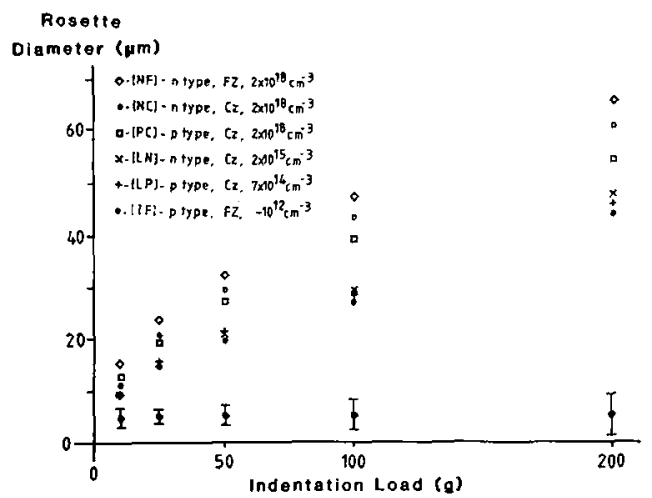

Fig. 2 - Size of rosettes (total side-to-side span) as a runction of load for the differently doped silicon specimens. Typical error bars (10) are shown for each load.

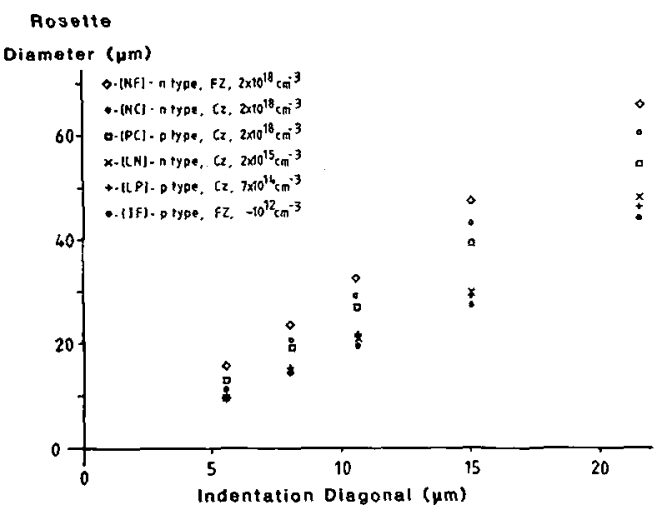

Fig. 3 - Size of rosettes as a function of indentation diagonal for the differently doped silicon specimens. Error bars as in fig. 2. Note the linear relationship for any given doping.

dislocation density at the ends of the rosette arms can be estimated from such micrographs, and such estimates were used here (see below).

Stress fields around indentations are not very well understood; however, two models based on rather different approaches have recently been developed by Chiang et al /14/ and Yoffe /15/. These models both give a residual stress field near the surface of the material consisting of a compressive radial stress and a tensile tangential stress, both decreasing as the third power of the distance from the indentation centre (in the elastically deformed region of interest here). As the dimensions and the crystallography of the rosettes are known, the indentation stress field can easily be resolved onto the active $\{111\}<1 \bar{l}$ < slip systems along the rosette arm length. The maximum resolved shear stress (RSS) is found to be that acting on the 

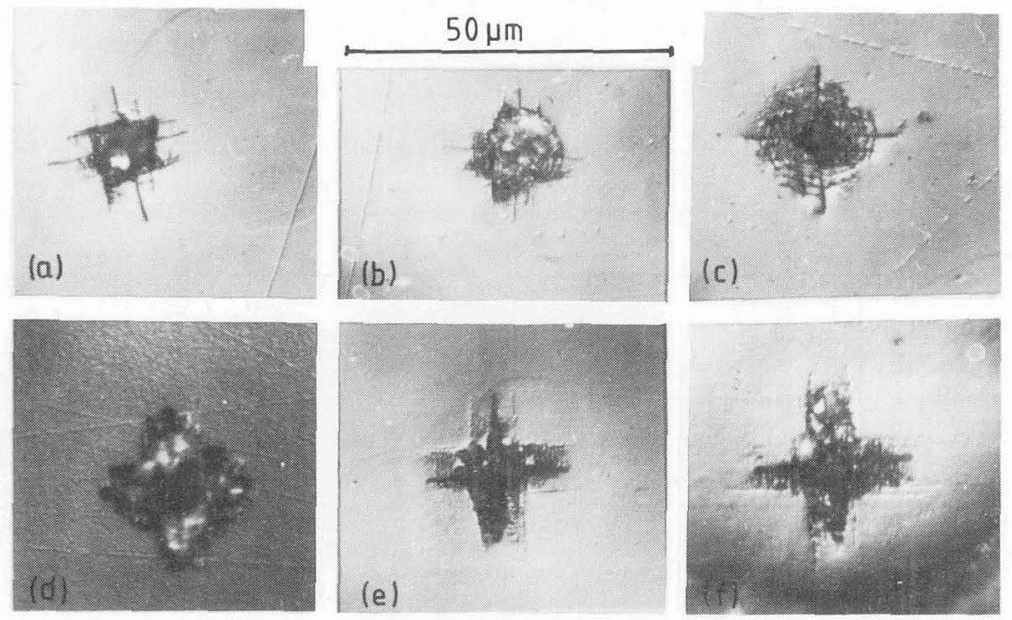

Fig. 4 - Typical rosettes, of doping: (a) IF; (b) LP; (c) LN; (d) PC; (e) NC; (f) NF. Optical micrographs, Nomarski differential interference contrast. The variation in rosette size with doping is clearly visible. Etch pit densities at the rosette ends appear to be $\sim 1-2 \mu \mathrm{m}^{-1}$.

dislocations with Burgers vectors directed away from the indentation centre. The variation of the RSS with distance along the rosette arms ( $x$ ) is complicated, but in the region of most interest, the RSS is roughly proportional to $x^{-3}$. ${ }^{5}$. If this stress field were the only one acting, then the rosette sizes of the differently doped silicon samples (see figures 2 and 3 ) would imply that the values of the RSS on the outermost dislocations vary by $\sim 400 \%$ with doping. However, the elastic interactions of the dislocations with each other significantly modify the simple indentation stress field.

Dislocation Interaction Model - Dislocation interactions were modelled by assuming that, for any dislocation outside the 'plastic zone' the combined indentation and dislocation stress fields are just sufficient to move the dislocation against a critical stress ' $\mathrm{crit}$, i.e. ' $\tau_{\mathrm{crit}}$ is the stress below which dislocation motion is not appreciable in the times in these experiments. Rosette size was found to be effectively independent of annealing time in the range 10 minutes to 5 hours. The dislocation loops were modelled as an array of straight dislocation lines in a single slip plane, acted on by the resolved shear stress from the residual indentation stress field and the stresses from their mutual elastic interactions. Since the dislocation loop diameter is comparable to the maximum distance between the loops, the replacement of the loops by straight dislocations in the model is justifiable as a first approximation. Image stresses were also neglected. Using a continuum model for the dislocation density, where the array of discrete dislocations is replaced by a density function, $\mathrm{N}(\mathrm{x})$, the model requires that:

$$
\tau_{\text {crit }}=\tau_{\left(x^{\prime}\right)}-\frac{\mu b}{2 \pi(1-\nu)}\left[\int_{x_{0}}^{X} \frac{N(x) d x}{x-x^{\prime}}-\int_{-x_{0}}^{-X} \frac{N(x) d x}{x-x^{\prime}}\right]
$$

where $x^{\prime}$ is the position of the dislocation under consideration (between the plastic zone boundary $\left(x_{0}\right)$ and $X$ (see figure 5)), $\tau\left(x^{\prime}\right)$ is the resolved residual indentation stress field from the plastic zone, $v$ is Poisson's ratio, $b$ is the magnitude of the Burgers vectors and $\mu$ is the shear modulus. The above formulation takes into account interactions between dislocations on both sides of the plastic zone. Similar 
Table 3 - Indentation Rosette Sizes and Derived Values of $\tau_{\text {crit }}$

\begin{tabular}{|c|c|c|c|c|c|c|c|}
\hline \multirow[t]{2}{*}{ Doping Type } & & \multicolumn{5}{|c|}{ Indentation Load (g) } & \multirow{2}{*}{$\begin{array}{l}\text { Mean* } \\
\tau \text { crit } \\
\text { (MPa) }\end{array}$} \\
\hline & & 10 & 25 & 50 & 100 & 200 & \\
\hline \multirow{2}{*}{ IF } & $\begin{array}{c}\text { Rosette } \\
\text { Width } \\
(\mu \mathrm{m})\end{array}$ & 9.7 & 14.5 & 19.8 & 27.4 & 44.2 & - \\
\hline & $\begin{array}{l}\tau_{\text {crit }} \\
(\mathrm{MPa})\end{array}$ & 106.7 & 106.5 & 102.6 & 104.8 & 94.4 & 102.7 \\
\hline \multirow{2}{*}{ LP } & $\begin{array}{l}\text { Rosette } \\
\text { Width } \\
(\mu \mathrm{m})\end{array}$ & 9.7 & 15.1 & 21.6 & 29.0 & 46.0 & - \\
\hline & $\begin{array}{l}{ }^{\tau} \text { crit } \\
\text { (MPa) }\end{array}$ & 106.7 & 101.0 & 95.8 & 99.1 & 91.7 & 98.7 \\
\hline \multirow{2}{*}{ LN } & $\begin{array}{c}\text { Rosette } \\
\text { Width } \\
(\mu \mathrm{m})\end{array}$ & 9.7 & 14.8 & 21.0 & 29.8 & 48.0 & - \\
\hline & $\begin{array}{l}\tau \text { crit } \\
(\mathrm{MPa})\end{array}$ & 106.7 & 102.7 & 98.0 & 97.0 & 88.8 & 98.6 \\
\hline \multirow{2}{*}{$\mathrm{PC}$} & $\begin{array}{l}\text { Rosette } \\
\text { Width } \\
(\mu \mathrm{m})\end{array}$ & 12.8 & 19.2 & 25.9 & 38.8 & 54.4 & - \\
\hline & $\begin{array}{l}{ }^{t} \text { crit } \\
(\mathrm{MPa})\end{array}$ & 86.2 & 85.8 & 83.8 & 80.9 & 81.4 & 83.0 \\
\hline \multirow{2}{*}{$\mathrm{NC}$} & $\begin{array}{l}\text { Rosette } \\
\text { Width } \\
(\mu \mathrm{m})\end{array}$ & 11.1 & 20.4 & 29.8 & 43.3 & 61.2 & - \\
\hline & $\begin{array}{l}{ }^{\tau} \text { crit } \\
(\mathrm{MPa})\end{array}$ & 95.7 & 82.3 & 76.6 & 75.5 & 75.6 & 77.5 \\
\hline \multirow{2}{*}{ NF } & $\begin{array}{l}\text { Rosette } \\
\text { Width } \\
(\mu \mathrm{m})\end{array}$ & 15.5 & 23.6 & 32.5 & 47.5 & 66.0 & - \\
\hline & $\begin{array}{l}\tau_{\text {crit }} \\
(\mathrm{MPa})\end{array}$ & 76.3 & 75.2 & 72.9 & 71.8 & 72.5 & 73.1 \\
\hline
\end{tabular}

* In calculating this mean value, the results from $10 \mathrm{~g}$ indentations were not included. 
equations, e.g. for dislocation pile-ups at precipitate particles, etc., have been solved by means of Hilbert transforms (e.g. Hirth and Lothe /16/). In this case, however, the equation was not solved analytically; a numerical method was used.

The method involved splitting the interval between the plastic zone boundary and the end of the dislocation array into a number of smaller intervals, of width $\Delta x$, within which the dislocation density was taken to be constant and equal to the value at the interval's midpoint $\left(x_{J}\right)$. The values of $\tau\left(x_{T}\right)$ were evaluated, as described above, for the interval endpoints (see figure 5). The integral above could then be evaluated for each value of $x_{I}$ as a sum:

$$
\tau_{\text {crit }}=\tau_{\left(x_{I}\right)}-\frac{\mu b}{2 \pi(1-v)} \sum_{J=0}^{J=n}\left[N\left(x_{J}\right) \Delta x \frac{1}{x_{J}-x_{I}}-\frac{i}{x_{J}+x_{I}}\right]
$$

There are $\mathrm{n}$ positionsat which $\mathrm{x}_{J}$ is evaluated; such sums lead to $\mathrm{n}$ equations in $\mathrm{n}$ unknowns, one of which is the value of $\tau_{\mathrm{crit}}$, and $(n-1)$ of which are the values of the dislocation density function at the interval midpoints (see figure 5). Such simultaneous equations are readily soluble by the standard methods; in this case the Numerical Algorithms routine FO4ATF was used as part of a larger FORTRAN program which also generated the values of $t\left(x_{I}\right)$ etc.

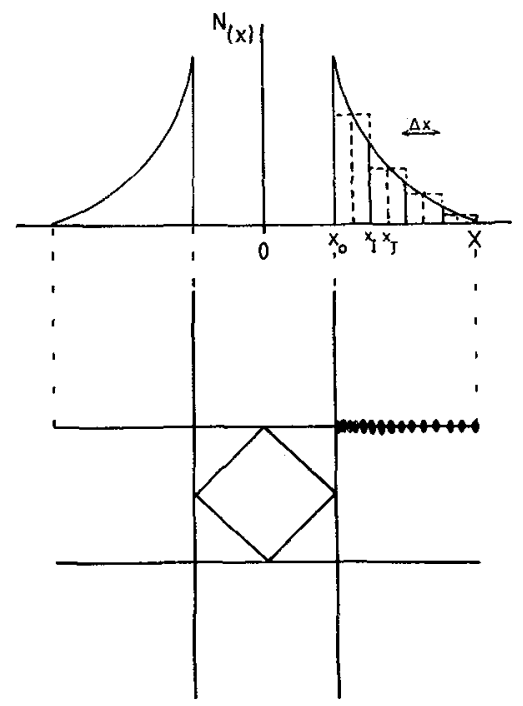

Fig. 5 - Method of solution for the dislocation density/critical stress. The plastic zone lies between $\pm x$; the indentation stress field is calculated at the interval ends $x_{I}$, and the solution is for the dislocation densities at the interval centres $x_{J}$ (see text).

The program allowed the operator to select values for the plastic zone size ( $x$ ). (i.e. the values of $x$ around the indentation within which the sum was not evaluated) and for the stress field scaling factor, $B$. The latter defined the strength of the stress field, at a radius $r$, as:

$$
\sigma=B \frac{a^{3}}{r^{3}}
$$


where ' $\mathrm{a}$ ' is a reference radius, made equal to the radius of a hemisphere of volume equal to that of the Vickers' indentation; the radial stress is equal to $\sigma$, and, following Yoffe $/ 15 /$, the tangential stress is taken to be $-2 / 7 \sigma$ (using $v=0.25$ ). The value of $n$ was also operator-defined. The values of $B$ and $x_{0}$ were then varied so as to fit the computed to the observed dislocation densities at the rosette arm ends (the only places where etch pit densities were low enough to allow such estimates, to be made); here the spacings were $1 / 2-1 \mu m$ (see figure 4 ).

It was found that variation of both the plastic zone width $\left(x_{0}\right)$ and the stress scaling factor (B) caused variation in the computed values for ${ }^{\top} \mathrm{crit}$ and the dislocation distribution. However, for fixed values of $x$ and $B$, the values of

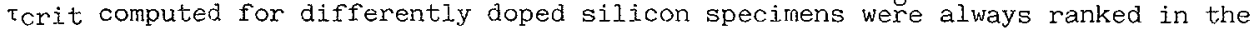
same order, and were in constant ratio to one another. It was found that $\mathrm{B}=10 \mathrm{GPa}$ and a plastic zone width equal to the width of the rosette arms (i.e. roughly equal to the indentation diagonal) gave dislocation densities of the right order, i.e. $1-2 \mu^{-1}$. Using these values, the data shown in figures 2 and 3 yield results as in table 3 .

The values of $\tau$ crit produced are proportional to the value of $B$ selected, as are the values for the dislocation distribution function. The variation of these with the selected plastic zone size is shown in table $4 ; x_{0}=0.5$ corresponds to the plastic zone being a square of side equal to the indentation diagonal. It can be seen from figure 4 that for $x<x_{0}=0.5$, intersection of slip systems from other parts of the rosette would render the simple model used here invalid. These intersections define a square area of dislocation interaction which could justifiably be taken as the intersection of the 'plastic zone' with the surface. On these grounds, it appears that $x_{0}=0.5$ is the best choice.

Table 4 - Variation of Solution with Plastic Zone Size

$\begin{array}{ccc}x_{0} & { }^{i} \operatorname{crit}(\mathrm{MPa}) & N(X)\left(\mu \mathrm{m}^{-1}\right) \\ 0.1 & 153.4 & 2.3 \\ 0.2 & 152.6 & 2.3 \\ 0.3 & 129.2 & 1.9 \\ 0.4 & 101.0 & 1.6 \\ 0.5 & 76.4 & 1.3 \\ 0.6 & 57.6 & 1.0 \\ 0.7 & 43.9 & 0.8\end{array}$

$x_{0}$ is expressed as a fraction of the indentation diagonal. Solutions are for: Load, 50g; Doping, NC; $B=10 \mathrm{GPa}$.

* Values of $x_{0}<0.1$ give unrealistic solutions with some values of $\mathrm{N}(\mathrm{x})$ becoming negative.

Comparison with Other Results - The solution above can be checked by comparison in two ways: (i) the derived values for $\tau$ crit can be compared with other experimental results for yield and flow stresses for silicon; (ii) the 'best fit' value of $B$, 10GPa, can be compared with values derived from detailed analytical solutions for residual indentation stress fields, such as those of Chiang et al /14/ or Yoffe/15/. Very little work has been performed on the flow of silicon at temperatures as low as those used here. However, the results of Pirouz/unpublished work/ from compression experiments at $420^{\circ} \mathrm{C}$ indicate that in intrinsic silicon, noticeable dislocation movement occurs at RSS's less than 170MPa. Wessel and Alexander /17/ deformed silicon using RSS's between 100 and $350 \mathrm{MPa}$ at $420^{\circ} \mathrm{C}$. Rabier / unpublished work/ from compression experiments on differently doped silicon specimens at $400^{\circ} \mathrm{C}$, found values of the lower yield stress equivalent to RSS's of $\sim 1000 \mathrm{MPa}$ for undoped, and $\sim 700 \mathrm{MPa}$ for heavily doped silicon. The results of Rabier involve rather higher stresses than those estimated from these experiments. However, the lower yield stress is not directly related to the critical stresses found by the technique used here; 
it would be expected to be rather higher, because of dislocation interaction in the relevant part of the stress-strain curve. It is interesting to note that the ratio of the flow stresses in his 'intrinsic' and heavily doped specimens is very similar to that of the maximum to the minimum values of ${ }{ }_{\text {crit }}$ found by the analysis here.

Comparison of the value of the 'stress scaling factor', B, used in this analysis with those calculated from analytical solutions of the residual indentation stress field may also be useful. The analyses of both Yoffe /15, private communication/ and Chiang et al /14/ give stress fields of magnitude equivalent to $B=40 G P a$. The 'good fit' value used here was 10GPa. This discrepancy may be accounted for by the reduction of the stress field due to the plastic zone by the punching out of dislocations and their movement through the supposedly purely elastically deformed regions around the indentation. A preliminary calculation indicates that such reductions are important, but that any more realistic model must take into account image stresses and the finite loop nature of the dislocations.

Summary and Conclusions - The size of indentation rosettes in silicon at $400^{\circ} \mathrm{C}$ varies with the doping of thee silicon. Rosettes are smallest in the intrinsic material, and are larger in heavily doped silicon. N-type dopants appear more effective than p-type dopants in this respect. These trends are qualitatively similar to those found for the effects of doping on dislocation velocity in silicon $/ 3 /, / 8 /$. Rosettes are slightly larger in float-zone silicon than in Czochralski silicon; this effect is presumably due to the difference in oxygen content between the two types. A similar effect has been found at higher temperatures by other workers 118/, /19/, but was unexpected at these low temperatures. Detailed analysis allows the relative critical stresses for dislocation motion ( $\tau_{\text {crit }}$ ) to be estimated. Fitting the strength of the stress field to the observed dislocation densities produces values for $\tau_{\mathrm{crit}}$ reasonably consistent with previously estimated values for comparable conditions. However, further work is needed to reconcile the estimated magnitude of the indentation stress field with those calculated analytically.

Acknowledgements - The work reported in this paper was supported by the SERC and the Venture Research Unit of BP plc. The assistance given to SGR by Dr E.H. Yoffe (indentation stress fields) and Dr D.P.A. Mayers (computer analysis) is gratefully acknowledged. The authors also thank Dr J. Rabier for provision of unpublished data from compression experiments.

\section{References}

/1/ ALEXANDER $\mathrm{H}$. and HAASEN P., Solid State Physics 22 (1968) 27.

/2/ PATEL J.R. and FREELAND P.E., Phys. Rev. Letts. 18 (1967) 833.

/3/ GEORGE A. and CHAMPIER G., Phys. Stat. Sol. $53 a$ (1979) 529.

/4/ FRISCH H.L. and PATEL J.R., Phys. Rev. Letts. 18 (1967) 784.

/5/ HAASEN P. J. Physique, colloque 40 (1979), C6-1 11 .

/6/ HIRSCH P.B., J. Physique, colloque 40 (1979), C6-117.

/7/ JONES R., Phil. Mag. 42B (1980) 213.

/8/ KULKARNI S.B. and WILLIAMS W.S., J. Appl. Phys. 47 (1976) 4318.

/9/ HIRSCH P.B., in Proc. Symposium on Defects in Semiconductors, Boston, Mass. 1980, Eds. J. Narayan and T.Y. Tan, Elsevier, North-Holland, 1981, p.257.

/10/ SECCO D'ARAGONA F., J. Electrochem. Soc. 119 (1972) 948.

/11/ HU S.M., Appl. Phys. Letts. 31 (1977) 139.

/12/ GILMAN J.J. and JOHNSTON W.J., in "Dislocations and Mechanical Properties of Crystals", Eds. J.C. Fisher, W.G. Johnston, R. Thomson and T. Vreeland, Wiley, 1957, p.116.

/13/ HU S.M., J. Appl. Phys. 46 (1973) 1470.

/14/ CHIANG S.S., MARSHALL D. B. and EVANS A.G., J. Appl. Phys. 53 (1982) 312.

/15/ YOFFE E.H., Phil. Mag. 46A (1982) 617.

/16/ HIRTH J.P. and LOTHE J., "Theory of Dislocations", McGraw-Hil1, 1968, p.694.

/17/ WESSEL K. and ALEXANDER H., Phil. Mag. 35A (1977) 1523.

/18/ HARADA H. and SUMINO K., J. Appl. Phys. $\overline{53}$ (1982) 4838.

119/ HU S.M. and PATRICK W.J., J. App1. Phys. 46 (1975) 1869. 